
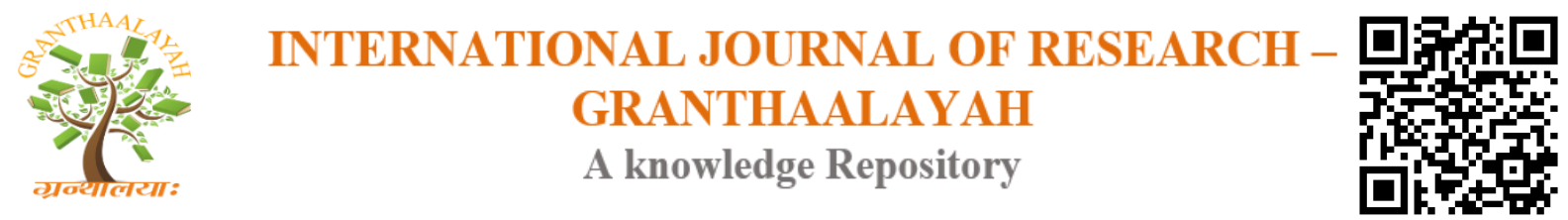

Management

\title{
BUILDING LOCAL RESILIENCE CAPACITY IN COMMUNITIES VULNERABLE TO FLOODS IN THE ORASHI REGION OF RIVERS STATE, NIGERIA
}

\author{
Ibama Brown ${ }^{1}$, Warebi G. Brisibe ${ }^{2}$ \\ ${ }^{1}$ Department of Urban and Regional Planning, Rivers State University, Port-Harcourt, Nigeria \\ ${ }^{2}$ Department of Architecture, Rivers State University, Port-Harcourt, Nigeria
}

\begin{abstract}
Building resilience capacities to survive flood disasters in vulnerable communities in the global south encompasses techniques that are unique to such communities. These strands of unique techniques are embedded in their indigenous knowledge as a people and revealed through the actions they display during such times of disaster. Data was obtained from four communities in the Orashi region in the aftermath of the 2012 floods in Nigeria, to investigate the techniques and actions adopted to help build local resilience capacity amongst vulnerable communities there. Interviews and focus groups were the primary means of data collection and analysis was done qualitatively. The findings revealed five key attributes the communities possessed that enabled them build their resilience capacity to cope with the flood disaster.
\end{abstract}

Keywords: Floods; Resilience; Capacity; Community; Vulnerability.

Cite This Article: Ibama Brown, and Warebi G. Brisibe. (2020). "BUILDING LOCAL RESILIENCE CAPACITY IN COMMUNITIES VULNERABLE TO FLOODS IN THE ORASHI REGION OF RIVERS STATE, NIGERIA." International Journal of Research Granthaalayah, 8(4), 297-312. https://doi.org/10.29121/granthaalayah.v8.i4.2020.35.

\section{Introduction}

This paper forms part of a much larger body of research on the analysis of power relations in flood disaster resilience in Rivers State. But the focus of this article is on how vulnerable and affected communities in the study region built local resilience capacities in the face of adversity. There is a growing body of knowledge that has identified actions taken by communities susceptible to flooding in the global south as indigenous to them, aimed at building their resilience capacities to flooding and other disasters. Most of the vulnerable communities have over the years continued to deploy series of actions that have become their inclination to build flood disaster resilience. Many communities in the Orashi region are precariously vulnerable whenever it floods and most of the people are vulnerable to the threats occasioned by the flood. However, there are some who seem to display characteristics to indicate that they are more resilient than others which has engendered differentials in their resilience capacities. 


\section{Literature Review}

The prolonged dearth of research evidence in the global south regarding differentials in flood disaster resilience capacities indicate a daunting challenge in identifying the causal factor of the differentials in flood disaster resilience in a homogenous terrain. However, literature that strengthened this research indicated four core constructs that are significantly useful in identifying the causal factors of such differentials in disaster resilience. It draws from: the perspective of human geography to identify what constitutes a community and the indicators of a resilient community (Knox and Pinch 2014; Brenner 2001; Daniels et al., 2001; Cloke et al., 1991); from sociology and anthropology, to understand how social relations and social resources contribute in the building of resilience (Della Porta and Diani 2009; Crossley 2002; Seale and Willis 1995; Berger and Luckmann 1991); psychology to evince how the perceptions of the individuals and communities enhance their resilience capacities (Cairns 2002; Mallak 1998); and from philosophy to indicate how perceptions of people metamorphose into social objects (Searle and Willis 1995; Berger and Luckmann 1991).

Seale and Willis (1995) describe the concepts of resilience, community and community resilience as human constructs that exist with distinct intellectual niches in which academia has elucidated their depth of understanding. These constructs are sparsely applied in empirical research relating to flood disaster resilience,yet they represent contemporary tools that support any appropriate theoretical framework inclined to empirical research (Peillon, 1998).

\section{Study Area}

Orashi region of Rivers State is the study area, it is in the Niger Delta region of Nigeria, and conservatively covers an approximate landmass of $70,000 \mathrm{~km} 2$ which represents one of the most extensive wetlands globally. It is an ecological zone located between latitude $4^{\circ}$ and $6^{\circ}$ North of the equator and longitude $5^{\circ}$ and $7^{\circ}$ East of Greenwich. It is also located on a coastal plain with fluvial deposits traversed by a number of rivers and tributaries which makes the area vulnerable to flooding (Mmom and Aifesehi, 2013). The Niger Delta consists of four ecological zones; lowland rainforest, freshwater swamp forests, mangroves and coastal barrier islands. It has dry and wet seasons, with poorly drained low-lying terrain and soil that encourages erosion and flooding occasioned by intense precipitation and river discharge in the wet season (Singh et al., 1995).

As a region, it comprises of four local government areas; Abua/Odual, Ahoada East, Ahoada West and Ogba/Egbema/Ndoniwith six distinct ethnic nationalities; Abua, Egi, Ekpeye, Engenni, Kugbo, and Odual with diverse social, cultural, economic and political orientations. For ease of access and coordination of the research, each of the four local government area represents a case study site. According to the 2006 national population commission census records, the region has a combined population of 983,170 persons (NPC 2006) who are predominantly agrarian and subsistence fisher folks.

Over the years the region has been continuously inundated with flood waters as a result of anthropogenic activities in the form of continuous agricultural activities, oil and gas exploration and exploitation leading to a loss in the vegetation (Uyigue and Agho, 2007). With the numerous anthropogenic activities, the flood susceptibility level in the region is very high because its coastal 
elevation lies between $4 \mathrm{~m}$ and $7 \mathrm{~m}$ which is significantly impacted by continual eustacy (Ochege et al., 2016). The nature of the terrain engenders tidal surges because of rising sea levels and sometimes after intense precipitation, the low lying coastal fringes submerge leading to flooding that could be as high as $3.2 \mathrm{~m}$ in some locations depending on the height (Mmom and Aifesehi, 2013).

Most vulnerable populations are faced with challenges arising from flooding which has become a constant phenomenon in their environment, with no help from any source to build their own resilience capacities or to put in place mitigation approaches (Tawari-Fufeyin et al., 2015). This scenario has caused most vulnerable communities to develop their resilience capacities to prevent the loss of livelihood sources as a community (McEwen et al., 2012; Demeritt 2012).

Vulnerability and resilience are two different yet related concepts that represent responses of actors and social systems regarding changes occasioned by surprises and shocks in the environment (Chacowry et al., 2018). Vulnerability expresses the state of individual and group susceptibility to danger, powerlessness and peculiarity to social and environmental changes occasioned by exposure to disturbances and the ability to adapt and build resilience capacities (Adger, 2006). In this context, vulnerable communities have incrementally continued to build their resilience capacities by adopting indigenous knowledge to combat the risk associated with the flood (Whatmore, 2009). Resilience as a notion stems from resistance, coping, adaptation and recovery (Zhou et al., 2010) which has over time gained several connotations based on contextual application of the notion (Rose 2007; Manyena 2006).

Resilience as an idea has had several meanings depending on the context and intent of the researcher. For Matyas and Pelling (2015), the application of resilience to natural hazards entails the ability of vulnerable communities to design how to cope, adapt, accommodate and recover from the consequences of a natural disaster. Timmerman (1981) was first to identify the need for designing a framework on how to cope, adapt, accommodate and recover from flood-related disasters. Such a framework witnessed incremental evolution over the years primarily in the global north enhanced by recorded achievements in science and technology. However, in the global south, there have been little improvements regarding the building of disaster resilience occassioned by the prevalence of the application of indigenous knowledge to build resilience capacities during and after any natural disaster which indicates the need for some form of external assistance (Chacowry et al., 2018).

\section{Resilience}

Resilience as a concept stems from the field of ecology and gained prominence in several fields like psychology and sociology. Resilience has been one of the main drivers in social sciences discourses relating to environmental planning, economic geography, psychology and disaster studies which have been using the concept prominently (Davoudi et al., 2012). The usage of the term resilience across various research fields has caused its definition to become indistinct (Cote and Nightingale 2012, Manyena 2006; Wreathall 2006, Pickett et al., 2004). Resilience generally, but not exclusively attributes its focus on the need to reduce damage in the eventuality of unexpected natural or anthropogenic distortions in the physical environment (Park et al., 2013; Zolli and Healy, 2012). 
Ungar (2008, p225) defined resilience as:

the context of exposure to significant adversity, whether psychological, environmental, or both, resilience is both the capacity of individuals to navigate their way to health-sustaining resources, including opportunities to experience feelings of well-being, and a condition of the individual family, community and culture to provide these health resources and experiences in culturally meaningful ways.

Resilience underpins the ability of affected vulnerable population to recover to near normal state of being after any disturbances. The social environment which encompasses culture, personal characteristics and family contributes significantly to the building of resilience (Ungar, 2008). Researchers have established a commonality in the building of resilience capacities in any disaster scenario which involves the mobilisation of resources, in addition to human adaptation structures that reflect the capacity to withstand and/or recover from any disaster or stress scenario (Chaskin 2008; Coleman and Hagell 2007; Wreathall 2006; Pickett et al., 2004; Kendra and Wachtendorf 2003).

Increasingly, resilience as a concept has gained global significance in its application by researchers because it involves the assemblage of both human and material resources, and in some situations presents adaptive strategies to withstand external and internal stressors in the environment. These stressors often distort socio-ecological systems to test the capacity to absorb anticipated and recurring disturbances (Adger et al., 2005). A detailed view of resilience literature evinced contrasting divides between researchers which indicates two polarities on the resilience spectrum. Such polarities stem from researchers who focus on adaptation enabled systems and researchers who focus on disaster recovery systems of resilience. These polarities are evident within the social non-equilibrium and social equilibrium concepts of resilience. Social non-equilibrium concept deals with a situation where resilience is established as the ability to adapt and change in a disaster scenario with no possibility of returning to the normal state, while the social equilibrium concept establishes resilience as the ability to return to the normal state after a disaster scenario (Pickett $e t$ al., 2004).

To establish these divides in a real-life scenario, a study to identify and establish embedded resilience capacities innate in the coping abilities of distraught social groups was carried out. It was further evident that adaptation strategies assisted in the establishment of resilience capacities by prompting control over any crises, a sense of belonging and a positive perception. An outcome of the study indicates that social groups display the social non-equilibrium form of resilience when faced with disturbances in real-life (Doron, 2005).

Doron (2005) generally underpins the notion that the process of building resilience should not be viewed as a regular adaptive procedure. Instead, the resilience building process should be viewed holistically as systems with the capability to adapt to situations beyond the threshold of their usual adaptive capability. Resilience from this perception elicits the attention in identifying the thresholds of present competence in order to understand the dynamics that go beyond the competency envelope for resilience (Woods, 2006). For Cairns (2002), the perception of Woods (2006) regarding resilience is a visible distinction which indicates phenomenal alteration of the traditional disaster risk management method. 


\section{Resilience in Disaster Management}

This study has been deliberately designed to explore resilience within the framework of communities vulnerable to flood disasters in the Orashi region of Rivers State, Nigeria. In the field of disaster management, several researchers have looked at the notion of resilience as it affects the individual and the community collectively (Anderson and Adey 2012; Dore and Etkin 2003; Kendra and Wachtendorf 2003; Paton and Johnson 2001; Paton et al., 2000). Researchers are of the opinion that contemporary flood disaster management system prevalent in most societies globally are tailored to be response-driven and excessively dedicated to actions regarding the outcome of any disaster (Oven et al., 2012; Bosher et al., 2007). In recent times a lot of vulnerability and risk reduction plan of actions have augmented the usual response-driven approaches to encourage resilience building in order to advance pre-disaster planning processes by vulnerable societies (Bosher et al., 2007).

Body of evidence from a number of studies indicate that response-driven approaches in managing disaster do not encourage the building of resilience in most vulnerable communities in the global south that are prone to disaster (Wilson 2012, Manyena 2006; Kendra and Wachtendorf 2003; Homan 2003; Pelling 2003; Paton et al., 2000). For instance, the study of Tobin and Whiteford (2002) on Ecuadorian communities affected by volcanic eruption indicates that the responsedriven approach to disaster management did not encourage the building of resilience capacities because of the negative effect of the evacuation experience on their psyche. These response-driven approaches indicated that disasters had instead an ephemeral 'therapeutic effect' (p28) which did not engender the development of resilience capacities of affected communities because of the collective humane behaviour and a sense of solidarity inherent among the affected community members. The outcome of the research underpins the fact that resilience-based process enhances an extended recovery outlook such that its absence often leads to delayed or partial recovery from a disaster.

At the turn of the last century, several community-based vulnerability and risk reduction schemes away from the resilience-based process emerged to augment existing traditional disaster management structures. These community-based vulnerabilities and risk reduction programmes focused more on the external factors such as risk and vulnerability amplification schemes that were beyond the control of the communities (Toft and Reynolds 2006; Quarantelli 2005; Turner and Pidgeon 1997). Such vulnerability and risk augmentation schemes were not enough to build the required resilience of both individual and the community. As such, further augmentations were required to achieve strong community and individual resilience which required sound policies, firm institutional practices and internal community structures during and after any crisis to enhance their resilience capacities (Oven et al., 2012). Researchers averred that the incorporation of the tenets of vulnerability and risk reduction into contemporary resilience building processes would enhance the implementation of both pre-disaster and post-disaster recovery programmes in vulnerable communities (Bosher et al., 2007). To achieve a holistic approach in the building of disaster resilience, Homan (2003) proposed the multiple standpoints approach which encompasses several actors on the team as the most suitable in disaster management as evident in most of the government and public policy driven frameworks. Instances of such multiple standpoint approaches are evident in parts of the emergency planning in the Civil Contingency Act 2004 of the United Kingdom (Anderson and Adey 2012). 


\section{Individual Resilience}

As the concept of resilience gains momentum globally, researchers are beginning to identify the importance of the connection between the individual, community and the institutions in building resilience during and after a disaster (Wilson 2012; Chaskin 2008; Doron 2005). For instance, Doron (2005) established that the best treatment for acute stress and trauma is individual resilience, but for long-standing stress occasioned by a disaster, community resilience aids recovery faster. Besides, people tend to develop meaningful relationships in an attempt to build personal resilience, while the support platform that aid such relationships are provided by institutions and communities for such relationships to thrive and encourage the building of resilience (Dolan, 2008). Resilience as a holistic and multifaceted paradigm encompasses the individual, community and the institution. To research the resiliency level of an individual, researchers have made three distinct stages of resiliency represented as the child, adolescent and adult (Coleman and Hagell 2007; Cairns 2002; Paton and Johnson 2001; Mallak 1998).

\section{Concept of Community}

Resilience is a dynamic and essential quality that is evident and necessary in every fabric of human society. The primary focus of this research hinges on power relations and differentials regarding collective resilience capacities of a community away from individual resilience capacities. Community resilience is often established through the ability of the community to harness resources internally in addition to the competence in the management of emerging challenges associated in the disaster (Hollnagel et al., 2007). In enhancing community resilience, Paton and Johnson (2001) specify three conditions that need to be in place which include:

- The maintenance of the means of access and use of resources by individuals;

- Protection of the physical environment; and

- To preserve organisational and economic integrity.

These three conditions enhance community resilience because they exist at interdependent levels within the community. For instance, the capacity of a vulnerable community to bounce back and/or bounce forward after every disaster scenario is dependent on the ability to deploy its resources. This would further require the protection of the physical environment, at the same time ensuring that there is continuity of the economic and administrative activities including social institutions and emergency management systems. Community resilience at this point also requires members of the vulnerable communities to have access to these resources and the requisite capacities to deploy both economic and physical resources with minimal difficulty. For a community to achieve extended resilience over time, there is a need for some inspiration that encourages members of the community to respond during a disaster through the formulation of encouraging intentions and convincing actions (Paton, 2003).

\section{Community Resilience}

Researchers have over the years viewed the community resilience discourse with a perception that resilience in a disaster scenario comes from the individuals within the community. Since resilience comes from the individual within the community, then collective actions among individuals instinctively translate to community resilience (Cairns 2002; Mallak 1998). Community resilience has some underpinning layers of individual activities which is a reflection of collective individual resilience capacities within the community (Doron 2005; Mallak 1998). Such underpinning layers revolve around the combination of potential and real resources, possession of durable networks 
and relationships which Bourdieu (1986) refers to as social capital. It has the potential of enhancing the resilience level of vulnerable communities at risk of any disaster. Community resilience is an indication of the ability of the community not to bounce back; rather, they bounce forward after any disaster episode. This is because 'bounce back' indicates the ability of the vulnerable to return to a pre-disaster state which is not achievable. It means they fail to come to terms with the present reality of devastation occasioned by the disaster. As the same time, bounce forward summarises community stability in the context of altered realities occasioned by the disaster scenario (Manyena, 2009).

It is imperative to state that community resilience is not a stand-alone notion; instead, physical and social components underpin it. The physical component involves taking into cognisance the ability of the physical structures within the community to withstand the impact of any disaster. The social mechanism involves considering the sensitivities of individuals and the entire community. It also involves the ability of community members to have a fair knowledge of the chronology, nature and magnitude of previous disasters that have befallen the community and the available social networks, norms, and forms of capital (Cohen et al., 2013). There are some characteristics inherent in a resilient community which is peculiar and crucial to the community because it marks the beginning of the collective will to sacrifice and survive in a disaster situation.

\section{Methodology}

Gathering the data for the study was done at different stages, but the study focused on four main case studies, from the four Local Government Areas in the Orashi region. There was a total of thirty-two interviews conducted; eight interviews for each local government area which involved community members, opinion leaders, traditional rulers, present and past political office holders. Others include one interview with the non-governmental organisations (NGOs), one from a faithbased organisation (FBO) and two from specialised government agencies that participated during the floods. Three out of the four proposed focus groups were successfully conducted. The process of recruiting the participants started with a meeting with the kings of each clan, who made referrals to the chairmen of the community development committee (CDC) in the particular community. The CDC chairman then contacted the town crier to proclaim around the community inviting those whose source of livelihood was affected during the flood. Those willing to participate in the research were asked to give their names and occupation to the CDC chairmen. After the submission, a second selection process was undertaken to get a balanced mix of participants based on their occupation and gender in order to get different perceptions of their experiences.

Other interviewees in the research participated through snowballing referrals from gatekeepers and other participants until saturation was achieved. These key gatekeepers were the kings of the clans in case study one and three, a former local government chairman in case study two who incidentally was the chairman during the flood. Interviewees who were representatives of the nongovernmental organisations (NGOs), faith-based organisations (FBOs), government ministries, departments and agencies (MDAs) were recruited to participate based on their level of participation during the flood, availability and willingness to participate in the research. Their willingness to participate was underpinned by the cordial relationship that had existed between them and the researcher who was a volunteer during the flood. 


\section{Analysis}

Analysis of the field data was done using deductive thematic analysis (top-bottom), but the process entails going through several stages. It started with several stages of reduction (coding) along the line of the theoretical framework. Other stages involve compressing the data before coding them to fit into the existing deduced themes.

\section{Findings}

Communities in the different case studies that are considered resilient are because of the attributes they exhibited during the flood. As stated earlier, there were four case studies in the Orashi region; each displayed with different levels of resilience capacities, hence the resilience differential. Nonetheless, the attributes that depict resilience have been picked from each individual case study. Such attributes were evident in the form of collective efficacy (Perkins and Long 2002), where the entire vulnerable communities trusted the king of the clan and collectively acted to build their resilience during the flood disaster that overwhelmed them. Their actions reflect the collective belief and collective actions inherent in most vulnerable rural communities in the global south which are often used to effectively handle environmental challenges occasioned by a natural disaster (Benight, 2004). Five key attributes that contributed to local resilience capacity, deduced from the study were; social capital, trustworthiness, leadership, indigenous knowledge and communal network. Each of these attributes has been discussed below accordingly.

\section{Social Capital}

Social capital is an intrinsic characteristic exhibited by these vulnerable rural communities during the flood disaster. It involved the possession of durable networks of more or less entrenched relationships that are mutually recognised by the principal actors in the field (Bourdieu 1986). For these communities, social capital represents the existing durable relationships that span across family members, community members, people within the same age group, and other social associations. Underlying these relationships is the existence of collective actions among members to handle their collective challenges when the need arises. Such relationships further engender communal cohesion among the members, which is often deployed to build their resilience capacities in times of a disaster. It is such that those within the same network (family, friends, community, social group and the like) often get priority attention before other vulnerable members of the community as evident from the field data. Communal interactions existed within the community between and among the vulnerable actors which is the arena that underpins the Bourdieusian field because actors deployed social positions in those communities. Deployment of social positions was done in order to access and control the available resources by the dominant actors at the same time the vulnerable population display some ingrained dispositions in accepting the activities of such actors in the field.. These communal actions of the actors contributed significantly in shaping and elucidating the characteristics of each of the identified fields in the end.

\section{Trustworthiness}

Trustworthiness is a component of social trust which is a reflection of individual and group anticipation of the mutual cooperativeness and efficacy expected from actors in the society. It reduces any impending relationship friction and encourages further social cohesion among 
members of a social network because of the underlying belief in the norm of reciprocity (Justwan et al., 2018). For instance, the king of the clan exhibited this intrinsic characteristic by ceding most of the resources that accrued to the people, and it was expected of the local government chairman to exhibit same by effectively managing the resources during the flood. However, that gesture of the king of the clan handing over the resources to the local government chairman indicates trustworthiness. It also encourages community resilience and aligns with the position of (Khunwishit et al., 2018) underpinning the significance of good leadership in enhancing resilience capacities of vulnerable communities. It represents a scenario where the trustworthiness of a leader in a social group engenders members to work collectively against collective challenges that might befall the group.

\section{Leadership}

Leadership entails the ability of an individual in charge of a social group to develop a clear and comprehensive system of expectations, and to identify and deploy the strengths of all available resources within an organisation to achieve a collective objective (Batten, 2001). In this scenario, the leadership capacities of the traditional actors enabled vulnerable people to build their resilience capacities in order to bounce forward after the flood disaster (Boin, 2010). The gesture of the king of the clan engenders social bonds among the members of the vulnerable communities in the study area. It underpins the fact that effective leadership contributes significantly to the building of disaster resilience in the global south. Entrusting an individual and group with the collective resources of a social group is strongly related to the leadership capacities possessed and displayed. Such privileges of taking charge of the collective resources also have the potential of building the resilience capacities of vulnerable population in a disaster situation. It stems from the fact that when trustworthy leaders take control of available resources, the sense of fulfilment sets in on the part of the vulnerable population. This perception further enhances the resilience capacities due to the therapeutic effects inherent in such perceptions because they are sure of being cared for by the king of the clan (Khunwishit et al., 2018; Batten 2001).

\section{Indigenous Knowledge}

Researchers have identified indigenous knowledge as a strategy deployed in surviving a disaster (McEwen and Jones 2012). Indigenous knowledge includes lay knowledge, traditional knowledge, inter-generational knowledge which has also proven to be a source of survival in a disaster (McEwen et al., 2017; Mavhura et al., 2013; McEwen and Jones 2012; Scammell et al., 2009). These forms of knowledge encourage the building of resilience capacities to flood disaster in the global southern context (Mavhura et al., 2013). In most circumstances, each of the vulnerable communities exhibit a central idea of seeking ingenious indigenous ways to build their resilience capacities since they have limited access to power structures. Seeking these ingenious indigenous ways of building resilience capacities to flood disaster in the absence of effective power structures and related resources has over the years become experimental and had gained currency as an emerging body of knowledge in the global south because it thrives on the evolving repetitive practices of the people (Tharakan 2015; Nakata et al., 2005). Besides, such experimental knowledge is contextual and engenders the community or individual to act on impulse when faced with danger occasioned by a disaster such as flooding (Spiekermann et al., 2015).

Indigenous knowledge was pivotal in the adaptation strategies adopted by vulnerable communities to build their resilience capacities during the flood disaster in case studies two and three. The 
knowledge was unique to them and not written down in any rulebook for others outside their clan to apply (Tran et al., 2009). Instead, the knowledge was applied tacitly by the people who have been inundated by the threats associated with the flood annually. As a tradition in most indigenous communities in the global south, there is hardly any documentation for their endeavours, neither do they attach patents and names to their discoveries. Since these adaptation strategies were indigenous to the affected people, they were devoid of any Western scientific knowledge from the universities, and it falls within the realm of indigenous technology (Flavier et al., 1995).

Being an agrarian society, the vulnerable people in case studies two and three have over the years developed the ingrained disposition of always preparing themselves with the deployment of their adaption strategies. These strategies include early planting and harvesting of their crops, the building of wooden piers to store farm produce and personal effects which had enabled them to build their resilience capacities to survive the threat occasioned by the floods. This approach to surviving consistent flood scenarios conforms with the position of Doron (2005) and Mallak (1998), where vulnerable communities build their resilience capacities with the adoption of indigenous strategies unique to them.

The application of indigenous knowledge to solve disaster-related threats has always been an indispensable component of building resilience capacities in most indigenous enclaves in the global south. Deploying indigenous knowledge by vulnerable population has gained prominence over the years occasioned by their limited access to resources and capacities concerning western flood mitigation strategies as indigenous people. Hence, they adapt and deploy systematic processes such that whenever there was any disaster-related crisis, most of the vulnerable among them organise themselves and apply such indigenous knowledge that makes them build their resilience capacities (Dekens, 2007).

\section{Communal Networks}

Communal networks, infused with social capital, played a vital role in the build-up to community resilience because vulnerable members in the same social network were given priority assistance before others outside their networks. This characteristic evinced bonding social capital (Hawkins and Maurer, 2009). The communal network in case study three and four does not portray the traditional perception of Bourdieu (1986) regarding what constitutes a communal network. It is because the network in the context of this research mostly arose as an offshoot of ill-disposed developments exhibited by the political actors regarding the resources. A community of crisis in the clan became evident when the resources were accessed and controlled by only the political actors and their associates. It further led to them being authoritative and less open to the opinion of the traditional actors and vulnerable population (Booth-Fowler, 1995). They deployed a high level of domination and deprivation such that dissenting opinions were not accepted, and it enabled the vulnerable population to reinforce their bonds in order to support themselves to survive the threat of the flood disaster. Succinctly put, there was bonding social capital among the actors.

Putnam (2000) described bonding social capital as an offshoot of the relationship existing among members of the same network. In this circumstance, it spanned the spectrum of relationships from family, friends, community, social circle and ethnic group. Instances of bonding social capital were evident during the 2012 flood episode in some of the case study sites under review. From field experiences in this research, bonding social capital was one of the fastest ways of building the 
resilience of the affected people. Bonding social capital in this context engendered the closeness of the vulnerable and affected individuals within the same network such as the family, friends and community to be formidable (Hawkins and Maurer 2010; Bourdieu 1992).

Another essential form of capital which came as another offshoot of communal network that was deployed by the vulnerable population during the flood disaster was intellectual capital. It entails a transformative knowledge that enables the processing of raw materials into a valuable resource Laihonen and Lönnqvist (2010) which was evident across the entire study area. Achieving a valuable resource in this context requires human competences at the individual and group levels as well as the ethics that bind them (Stewart and Ruckdeschel, 1998). In this scenario, intellectual capital involved the conversion of the information about the flood received in the English language which represents the raw material. It was converted into the native dialect of the people which automatically became a valuable resource to the vulnerable people as everybody within the affected communities got the messages and moved as directed.

The human resource required to enable the completion of the intellectual capital cycle in this context were the primary actors like the kings of the clans in case study one and two, and the political actors in case study three and four. These primary actors did the conversion of the information from the English language into the native dialects of the people and passed the same information to the town crier to disseminate to the affected people. These commendable gestures contributed to building a more resilient population with improved resilience capacities as they prepared to move away from the flood disaster to safer grounds. Furnished with this information the people were able to prepare themselves enough to reduce the human casualty to the barest minimum. Social networks enabled the affected people to survive and bounce forward after the flood while the political and traditional actors were struggling with their social positions to access symbolic capitals converted to symbolic power in the field. It is evident that there is a nexus between indigenous knowledge and intellectual capital in the building of disaster resilience capacities in the global south away from scientific knowledge of flood disaster management.

\section{Discussion}

This research worked to develop a deepened understanding of how individuals and communities can enhance their resilience capacities through actions that engender social capital derived from collective community actions. Findings further indicated that the ways of building resilience capacities as evident in each case study site are the result of the common practice of the vulnerable local populace, in addition to the dominant actors and responses of the vulnerable people during and after the flood disaster. Social capital through their networks and norms of reciprocity was one common form of capital that was deployed in the study area to build their resilience capacities. On the part of the traditional actors, they deployed cultural and intellectual capitals to encourage the vulnerable population to shore up their resilience capacities. The application of symbolic power contributed to the building of resilience capacities of the vulnerable people as evident in the case studies.

In the course of exploring further shreds of evidence regarding indigenous resilience capacities in each of the case study sites, there were strands of evidence found by the author regarding divergence in references as to what best described indigenous adaptations of the vulnerable 
population to building resilience capacities as a norm of reciprocity. Such actions are indications that resonated with findings from some recent research. Mackinnon and Derickson (2013) effectively summarised this perspective by relating it to how the norm of resilience in UK government policy sprouts from an unsophisticated conviction that community resilience is "assumed to be always a positive quality, imbued with notions of individual self-reliance and triumph over adversity" (MacKinnon and Derickson 2013, p 259).

The authors view the bifurcation of research threads as focusing either on the resilience building process or the resilience outcome in itself, which has the potential of producing findings that interpret the struggle for resources consequent on unexpected levels of community resilience as a negative outcome. In this research, the assertion that vulnerable communities deployed unsophisticated indigenous approaches to build community resilience was proven to be valid because their ingrained dispositions have been a way of life that has helped them over the years in any disaster scenario.

Case study data has minimal evidence that indicates any negative connotations of resilience as may have been envisaged. However, all the interviews and focus group discussions indicate evidence of community actions aimed at building resilience capacities as an adaptation to survive the disaster scenario. The authors assert that findings from this research suggested that some powerful actors in the field tried to weaken the resilience capacities of the vulnerable communities through deliberate deprivation of resources that would have enhanced their resilience capacities during the flood disaster (as evidenced by case study 4 in Ogba/Egbema/Ndoni local government area). This perception draws a parallel with Bene et al., (2012), who indicated that powerful actors and institutions occasionally desire to weaken the resilience capacities of communities in order to impose a perceived transformative process within the community.

\section{Conclusions}

The notion of building resilience capacities of vulnerable people through a resilience weakening process is a novelty that has not been sufficiently articulated in most academic literature. It is such that vulnerable people devise indigenous ways to build resilience capacities in a disaster scenario. In this article, the analysis of the resilience capacities of vulnerable communities indicate that building resilient capacities involve input from multiple stakeholders but primarily, traditional actors such as the members of the community, the Community Development Committee (CDC), the traditional actors in the form of kings and clan heads, specialized government agencies, FBOs

and NGOs to form a durable resilience framework that would in future enhance the resilience capacities of such vulnerable communities

\section{References}

[1] Adger, W.N. "Vulnerability", Global Environmental Change, vol. 16, no. 3, 2006, pp. 268-281.

[2] Anderson, B. \& Adey, P. 2012, "Governing events and life: 'Emergency in UK Civil Contingencies", Political Geography, vol. 31, no. 1, 2012, pp. 24-33.

[3] Batten, J.D. 2001, Tough-minded leadership, Wipf and Stock Publishers.

[4] Benight, C.C. 2004, "Collective efficacy following a series of natural disasters", Anxiety, Stress \& Coping, vol. 17, no. 4, 2004, pp. 401-420. 
[5] Berger, P.L. \& Luckmann, T. The social construction of reality: A treatise in the sociology of knowledge, 1991, Penguin United Kingdom.

[6] Booth-Fowler, R. "Communities: Reflections on a definition", in Etzioni A (ed) "New Communitarian Thinking: Persons", Virtues, Institutions and Communities, University Press of Virginia, Virginia, USA, 1995, pp.88-95.

[7] Bourdieu, P. "The forms of capital (English version)", Handbook of theory and research for the sociology of education, 1986, pp. 241-258.

[8] Bourdieu, P. The practice of reflexive sociology (The Paris workshop). An invitation to reflexive sociology, 1992, pp. 216-260.

[9] Brenner, N. "The limits to scale? Methodological reflections on scalar structuration", Progress in Human Geography, vol. 25, no. 4, 2001, pp. 591-614.

[10] Béné, C., Wood, R.G., Newsham, A. \& Davies, M. "Resilience: new utopia or new tyranny? Reflection about the potentials and limits of the concept of resilience in relation to vulnerability reduction programmes", IDS Working Papers, vol. 2012, no. 405, pp. 1-61.

[11] Boin, A. "Designing resilience: Leadership challenges in complex administrative systems", Designing resilience: Preparing for extreme events, University of Pittsburgh Press, 2010, pp. 129141.

[12] Bosher, L., Carrillo, P., Dainty, A., Glass, J. \& Price, A. "Realising a resilient and sustainable built environment: towards a strategic agenda for the United Kingdom", Disasters, vol. 31, no. 3, 2007, pp. 236-255.

[13] Cairns, K. "Attachment, trauma and resilience" British Association for Adoption \& Fostering, 2002, London.

[14] Chacowry, A., McEwen, L.J. \& Lynch, K. "Recovery and resilience of communities in flood risk zones in a Small Island Developing State: A case study from a suburban settlement of Port Louis, Mauritius", International Journal of Disaster Risk Reduction, vol. 28, 2018, pp. 826-838.

[15] Chaskin, R.J. "Resilience, community, and resilient communities: Conditioning contexts and collective action", Child Care in Practice, vol. 14, no. 1, 2008, pp. 65-74.

[16] Cloke, P.J., Philo, C. \& Sadler, D. "Approaching human geography an introduction to contemporary theoretical debates", 1991, Chapman, London.

[17] Cohen, O., Leykin, D., Lahad, M., Goldberg, A. \& Aharonson-Daniel, L. "The conjoint community resiliency assessment measure as a baseline for profiling and predicting community resilience for emergencies", Technological Forecasting and Social Change, vol. 80, no. 9, 2013, pp. 1732-1741.

[18] Coleman, J. \& Hagell, A. "The nature of risk and resilience in adolescence", Adolescence, risk and resilience: Against the odds, vol. 3, 2007, pp. 2-16.

[19] Cote, M. \& Nightingale, A.J. "Resilience thinking meets social theory: situating social change in socio-ecological systems (SES) research", Progress in Human Geography, vol. 36, no. 4, 2012, pp. 475-489.

[20] Crossley, N. Making sense of social movements, 2002, McGraw-Hill Education (UK).

[21] Daniels P, Bradshaw M, Shaw D and Sidaway J. 2001, "Human Geography - issues for the 21st Century", Pearson Education, Harlow

[22] Davoudi, S., Shaw, K., Haider, L.J., Quinlan, A.E., Peterson, G.D., Wilkinson, C., Fünfgeld, H., McEvoy, D., Porter, L. \& Davoudi, S. "Resilience: A Bridging Concept or a Dead End?"Reframing" Resilience: Challenges for Planning Theory and Practice Interacting Traps: Resilience Assessment of a Pasture Management System in Northern Afghanistan Urban Resilience: What Does it Mean in Planning Practice? Resilience as a Useful Concept for Climate Change Adaptation? The Politics of Resilience for Planning: A Cautionary Note: Edited by Simin Davoudi and Libby Porter", Planning Theory \& Practice, vol. 13, no. 2, 2012, pp. 299-333.

[23] Dekens, J. Local knowledge for disaster preparedness: a literature review, International Centre for Integrated Mountain Development (ICIMOD), 2007, Kathmandu

[24] Della Porta, D. \& Diani, M. Social movements: An introduction, 2009, John Wiley \& Sons. 
[25] Demeritt, D. "The perception and use of public weather services by emergency and resiliency professionals in the UK", Report for the Met Office Public Weather Service Customer 2012, Group, vol. 2.

[26] Dolan, P. "Prospective possibilities for building resilience in children, their families and communities", Child Care in Practice, vol. 14, no. 1, 2008, pp. 83-91.

[27] Doron, E. "Working with Lebanese refugees in a community resilience model", Community Development Journal, vol. 40, no. 2, 2005, pp. 182-191.

[28] Flavier, J.M., Jesus, A.D. \& Navarro, C.S. "The regional program for the promotion of indigenous knowledge in Asia". In: D. Warren, L Slikkerveer and D. Brokensha (eds.), The Cultural Dimension of Development: Indigenous knowledge systems 1995, pp. 479-487, London: Intermediate Technology Publications.

[29] Hawkins, R.L. \& Maurer, K. "Bonding, bridging and linking: how social capital operated in New Orleans following Hurricane Katrina", British Journal of Social Work, vol. 40, no. 6, 2010, pp. 1777-1793.

[30] Homan, J. 2003, "The social construction of natural disaster: Egypt and the UK" in Natural Disaster and Development in a Globalizing World Routledge, pp. 157-172.

[31] Justwan, F., Bakker, R. \& Berejikian, J.D. "Measuring social trust and trusting the measure", The Social Science Journal, vol. 55, no. 2, 2018, pp. 149-159.

[32] Kendra, J.M. \& Wachtendorf, T. "Elements of resilience after the world trade center disaster: reconstituting New York City's Emergency Operations Centre", Disasters, vol. 27, no. 1, 2003, pp. 37-53.

[33] Khunwishit, S., Choosuk, C. \& Webb, G. "Flood Resilience Building in Thailand: Assessing Progress and the Effect of Leadership", International Journal of Disaster Risk Science, vol. 9, no. 1,2018, pp. 44-54.

[34] Knox, P. \& Pinch, S. Urban social geography: an introduction, 2014, Routledge.

[35] MacKinnon, D. \& Derickson, K.D. 2013, "From resilience to resourcefulness: A critique of resilience policy and activism", Progress in Human Geography, vol. 37, no. 2, 2013, pp. 253-270.

[36] Mallak, L.A. "Measuring resilience in health care provider organisations", Health manpower management, vol. 24, no. 4, 1998, pp. 148-152.

[37] Manyena, B. Disaster resilience in development and humanitarian interventions, 2009, (Doctoral dissertation, Northumbria University).

[38] Manyena, S.B. "The concept of resilience revisited", Disasters, vol. 30, no. 4, 2006, pp. 434-450.

[39] Matyas, D. \& Pelling, M. "Positioning resilience for 2015: the role of resistance, incremental adjustment and transformation in disaster risk management policy", Disasters, vol. 39, no. s1, 2015, pp. s1-s18.

[40] Mavhura, E., Manyena, S.B., Collins, A.E. \& Manatsa, D. "Indigenous knowledge, coping strategies and resilience to floods in Muzarabani, Zimbabwe", International Journal of Disaster Risk Reduction, vol. 5, 2013, pp. 38-48.

[41] McEwen, L. \& Jones, O. "Building local/lay flood knowledge into community flood resilience planning after the July 2007 floods, Gloucestershire, UK", Hydrology Research, vol. 43, no. 5, 2012, pp. 675-688.

[42] McEwen, L., Garde-Hansen, J., Holmes, A., Jones, O. \& Krause, F. "Sustainable flood memories, lay knowledges and the development of community resilience to future flood risk", Transactions of the Institute of British Geographers, vol. 42, no. 1, 2017, pp. 14-28.

[43] Mmom, P.C. \& Aifesehi, P.E. "Vulnerability and resilience of niger delta coastal communities to flooding", IOSR Journal of Humanities and Social Science, vol. 10, 2013, pp. 27-33.

[44] Nakata, M., Byrne, A., Nakata, V. \& Gardiner, G. "Indigenous knowledge, the library and information service sector, and protocols", Australian Academic \& Research Libraries, vol. 36, no. 2, 2005, pp. 7-21. 
[45] Ochege, F.U., Wekpe, V.O. \& Obafemi, A.A. "An Overview of Flood Vulnerability Mapping: strategy for Disaster Risk Reduction in the Niger Delta Region, Nigeria", Nigerian Journal of Hydrological Sciences, vol. 4, no. 1, 2016, pp. 13-26.

[46] Oven, K.J., Curtis, S.E., Reaney, S., Riva, M., Stewart, M.G., Ohlemüller, R., Dunn, C.E., Nodwell, S., Dominelli, L. \& Holden, R. "Climate change and health and social care: Defining future hazard, vulnerability and risk for infrastructure systems supporting older people's health care in England", Applied Geography, vol. 33, 2012, pp. 16-24.

[47] Paton, D. "Stress in disaster response: a risk management approach", Disaster Prevention and Management: An International Journal, vol. 12, no. 3, 2003, pp. 203-209.

[48] Paton, D. \& Johnston, D. "Disasters and communities: vulnerability, resilience and preparedness", Disaster Prevention and Management: An International Journal, vol. 10, no. 4, 2001, pp. 270-277.

[49] Peillon, M. "Bourdieu's field and the sociology of welfare", Journal of social policy, vol. 27, no. 2, 1998, pp. 213-229.

[50] Pelling, M. Natural disaster and development in a globalizing world, 2003, Routledge, New York, and London, UK.

[51] Perkins, D., \& Long, D. Neighborhood sense of community and social capital: A multi-level analysis. In A. Fisher, C. Sonn, \& B. Bishop (Eds.), Psychological sense of community: Research, applications, and implications. New York: Plenum, 2002, pp. 291-318.

[52] Pickett, S.T., Cadenasso, M.L. \& Grove, J.M. "Resilient cities: meaning, models, and metaphor for integrating the ecological, socio-economic, and planning realms", Landscape and Urban Planning, vol. 69, no. 4, 2004, pp. 369-384.

[53] Putnam, R.D. "Bowling alone: America's declining social capital" in Culture and politics Springer, 2000, pp. 223-234.

[54] Quarantelli, E.L. What is a disaster? a dozen perspectives on the question, 2005, Routledge.

[55] Rose, A. "Economic resilience to natural and man-made disasters: Multidisciplinary origins and contextual dimensions", Environmental Hazards, vol. 7, no. 4, 2007, pp. 383-398.

[56] Scammell, M.K., Senier, L., Darrah-Okike, J., Brown, P. \& Santos, S. "Tangible evidence, trust and power: public perceptions of community environmental health studies", Social science \& medicine, vol. 68, no. 1, 2009, pp. 143-153.

[57] Searle, J.R. \& Willis, S. The construction of social reality, 1995, Simon and Schuster.

[58] Singh, J., Moffat, D. \& Linden, O. Defining an environmental development strategy for the Niger Delta, 1995, World Bank.

[59] Spiekermann, R., Kienberger, S., Norton, J., Briones, F. \& Weichselgartner, J. "The DisasterKnowledge Matrix-Reframing and evaluating the knowledge challenges in disaster risk reduction", International Journal of Disaster Risk Reduction, vol. 13, 2015, pp. 96-108.

[60] Stewart, T. \& Ruckdeschel, C. Intellectual capital: The new wealth of organisations. Performance Improvement, vol. 37, no.7, 1998, pp.56-59.

[61] Tawari-Fufeyin, P., Paul, M. \& Godleads, A.O. "Some aspects of a historic flooding in Nigeria and its effects on some Niger-Delta Communities", American Journal of Water Resources, vol. 3, no. 1, 2015, pp. 7-16.

[62] Tharakan, J. "Indigenous knowledge systems-A rich appropriate technology resource", African journal of science, technology, innovation and development, vol. 7, no. 1, 2015, pp. 52-57.

[63] Timmerman, P. "Vulnerability resilience and collapse ofsociety", A ReviewofModels and Possible Climatic Appli-cations. 1981, Toronto, Canada. Institute for Environmental Studies, University of Toronto,

[64] Toft, B. \& Reynolds, S. "Learning from Disaster: A Management Approach", (3rd ed), 2006, Hampshire, England: Macmillan.

[65] Tobin, G.A. \& Whiteford, L.M. "Community resilience and volcano hazard: the eruption of Tungurahua and evacuation of the faldas in Ecuador", Disasters, vol. 26, no. 1, 2002, pp. 28-48.

[66] Turner, B.A. \& Pidgeon, N.F. Man-made disasters, 2nd ed. 1997, Butterworth-Heinemann Oxford 
[67] Tran, P., Takeuchi, Y. \& Shaw, R. "Indigenous knowledge in river basin management", In Indigenous Knowledge and Disaster Risk Reduction: From Practice to Policy, Nova Science Publishers, New York, 2009, pp. 45-58.

[68] Ungar, M. "Resilience across cultures", The British Journal of Social Work, vol. 38, no. 2, 2008, pp. 218-235.

[69] Uyigue, E. \& Agho, M. "Coping with climate change and environmental degradation in the Niger Delta of southern Nigeria", Community Research and Development Centre Nigeria (CREDC), 2007, pp. 24-27.

[70] Whatmore, S.J. "Mapping knowledge controversies: science, democracy and the redistribution of expertise", Progress in Human Geography, vol. 33, no. 5, 2009, pp. 587-598.

[71] Woods D.D. "Essential characteristics of resilience", in: Hollnagel E, Woods DD and Leveson N (Eds) "Resilience Engineering", Ashgate Publishing Ltd, Aldershot, 2006, pp. 21-34

[72] Wreathall, J. "Properties of resilient organisations: an initial view", Resilience engineering: Concepts and precepts, 2006, pp. 275-285.

[73] Wilson, G. Community resilience and environmental transitions, 2012, Oxford, UK: Earthscan

[74] Zhou, H., Wan, J. \& Jia, H. "Resilience to natural hazards: a geographic perspective", Natural Hazards, vol. 53, no. 1, 2010, pp. 21-41.

[75] Zolli, A. \& Healy, A.M. Resilience: Why things bounce back, 2012, Simon and Schuster, Hachette UK.

\footnotetext{
*Corresponding author.

E-mail address: briswares@yahoo.com
} 